\title{
The Utility of Positron Emission Tomography (PET) Surveillance Following Definitive Therapy For Merkel Cell Carcinoma - An Australian Case Series
}

\author{
Katrina Diamante ${ }^{1,2}$, Amelia M Hollands ${ }^{3}$, Christina A Anthony ${ }^{4}$ and Gerald B Fogarty ${ }^{* 1-3,5,6}$ \\ ${ }^{1}$ Melanoma and Skin Cancer (MASC) Trials Limited, Melbourne, Australia \\ ${ }^{2}$ Australasian Merkel Cell Carcinoma Interest Group (AMIGOs), Australia \\ ${ }^{3}$ Genesis Care NSW, Sydney, Australia \\ ${ }^{4}$ Department of Radiation Oncology, Westmead Hospital, Sydney, Australia \\ ${ }^{5}$ St Vincent's Hospital Sydney, Sydney Australia \\ ${ }^{6}$ University of Technology Sydney, Sydney, Australia
}

*Corresponding author: Gerald B Fogarty, Department of Radiation Oncology, Melanoma and Skin Cancer Trials (MASC) Limited, Australasian Merkel Cell Carcinoma Interest Group (AMIGOs), Genesis Care, Australia

\section{ARTICLE INFO}

Received: March 15, 2019

Published: March 25, 2019

Citation: Katrina Diamante, Amelia M Hollands, Christina A Anthony, Gerald B Fogarty. The Utility of Positron Emission Tomography (PET) Surveillance Following Definitive Therapy For Merkel Cell Carcinoma - An Australian Case Series. Biomed J Sci \& Tech Res 16(3)-2019. BJSTR. MS.ID.002841.

Abbreviations: CT: Computed Tomography; F: Female; FDG: Fluorodeoxyglucose; Gy: Gray; Immuno: Immunotherapy; M: Male; MCpyV: Merkel Cell Polyomavirus; MCC: Merkel Cell Carcinoma; PET: Positron emission tomography; Pt: Patient; +ve: Positive; RT: Radiotherapy; SBRT: Stereotactic Body Radiotherapy; Sx: Surgery; Rx: Treatment; Unk: Unknown; UV: Ultraviolet; WLE: Wide Local Excision
ABSTRACT

Introduction: Merkel cell carcinoma (MCC) is a rare, highly aggressive neuroendocrine tumour of the skin. MCC has a mortality rate higher than melanoma, and a high proportion of patients succumb to metastatic disease. Close follow-up following initial treatment is needed. 18-Fluorodeoxyglucose (FDG) Positron Emission Tomography (PET) is often used in surveillance post-definitive treatment, but published data supporting this practice is lacking. This retrospective, single clinician study is a case series documenting the utility of PET in this scenario.

Methods: Medical records of a clinician, who sees on average five new MCC cases per year, with $80 \%$ being treated with radical intent, were searched over a five-year period (2014-2018). Cases post-initial therapy, who had a routine surveillance PET when asymptomatic that discovered more disease, and as a result changed management, were sought.

Results: Five cases were found of patients treated with radical intent who had a routine surveillance PET scan when asymptomatic that discovered more disease and as a result, changed management. This represented $25 \%$ of radical cases and $20 \%$ of all cases. The cases are described in detail.

Conclusion: This retrospective study of a single clinician's practice shows that routine surveillance PET scans may change management in up to $25 \%$ of asymptomatic MCC patients treated with radical intent. This finding adds weight to have PET scans in this scenario funded.

Keywords: Merkel Cell Carcinoma; Radiotherapy; Positron Emission Tomography; Australia; Follow-Up

\section{Introduction}

Merkel cell carcinoma (MCC) is a rare, highly aggressive neuroendocrine tumour of the skin [1,2]. Australia has the highest incidence in the world [3]. Risk factors for poor outcomes include advanced age [4] immunosuppression [5] and Merkel cell polyomavirus (MCPyV) infection [6-8]. MCC is prone to recurrence with a high proportion of patients succumbing to metastatic disease 
$[4,9]$. Close follow-up following initial treatment is important, including imaging. Poulsen et al showed 18-Fluorodeoxyglucose (FDG) Positron Emission Tomography (PET) to be a useful functional imaging modality for MCC staging [10]. This paper describes five cases where surveillance PET scanning on asymptomatic patients after initial treatment was performed as part of one clinician's follow-up protocol. These scans changed the management of these patients with MCC. This case series adds to the argument of the importance of funding surveillance PET scans in MCC.

\section{Methods}

Medical records of a radiation oncologist, with an interest in MCC, were searched over the years 2014-2018. This clinician sees on average five new MCC cases per year, with $80 \%$ being treated with radical intent. The follow-up protocol in this practice is a surveillance PET scan every 6 months following completion of definitive initial treatment, irrespective of whether symptoms or signs are present. Patients with MCC who had a PET scan when asymptomatic, that discovered new disease and changed management, were specifically sought.

\section{Results}

Five cases were found of patients who had a surveillance PET scan when asymptomatic that discovered more disease and, as a result, changed management. They represent $25 \%$ of radical cases and $20 \%$ of all cases seen during that time. These cases are detailed below:

\section{Case One}

A 64-year-old Vietnamese woman had multiple surgeries on her right eyelid for what was thought to be recurrent poorly differentiated cutaneous squamous cell carcinoma. Histopathology review revealed margin-positive MCC. PET scan prior to radiotherapy (RT) found no distant disease, making initial staging T1N0 (AJCC 8th edition) [11]. Superficial RT to the right eyelid to a total dose of 50Gy in 25 fractions was given. She had already palpable recurrence at the beginning of the RT, which resolved completely during RT. Six months later, she had a routine PET as part of follow-up. This found regional recurrence in the posterior orbit, and she was treated with curative intent with surgical resection and post-operative RT, followed by immunotherapy. She eventually succumbed to brain metastases a year after completion of her salvage local therapy, 30 months after her first initial surgery.

\section{Case Two}

An 81-year-old Caucasian male had a $10 \mathrm{~mm}$ MCC staged as T1N0 removed from his right middle finger with a wide local excision (WLE) and flap repair. He was treated with adjuvant RT to the ipsilateral epitrochlear node and axilla, all in continuity, to a total dose of 50Gy in 25 fractions. He was then followed with routine PETs every six months. At 24 months, he was noted on PET to have an asymptomatic, solitary distant recurrence in the right adrenal gland, biopsy-proven as MCC. This lesion had grown in six months after a negative PET. He then had stereotactic body radiotherapy (SBRT) to that lesion followed by immunotherapy with complete metabolic response on PET four months after SBRT. He continues with stable disease in the right adrenal mass on computed tomography (CT) scan, cold on PET, five years after original diagnosis.

\section{Case Three}

A 73-year-old Caucasian male had a $15 \mathrm{~mm}$ primary excised from the left thigh. Baseline PET was negative. WLE and sentinel node biopsy showed two impalpable nodes positive in the left groin, staged as T1pN1a. He was treated with adjuvant RT to the primary site and a discontinuous field to the left groin to a total dose of 50Gy in 25 fractions. Routine PET surveillance at 24 months revealed a 3 cm solitary distant recurrence with SUV 6.8 maximum in the paraaortic lymph nodes that had arisen within 3 months from the last PET. He was treated with immunotherapy and, during one of the breaks of immunotherapy, had SBRT to that node to a total dose of $30 \mathrm{~Gy}$ in 5 fractions. He continues with no evidence of disease; 30 months post initial diagnosis and 6 months after the para-aortic recurrence (Figure 1).
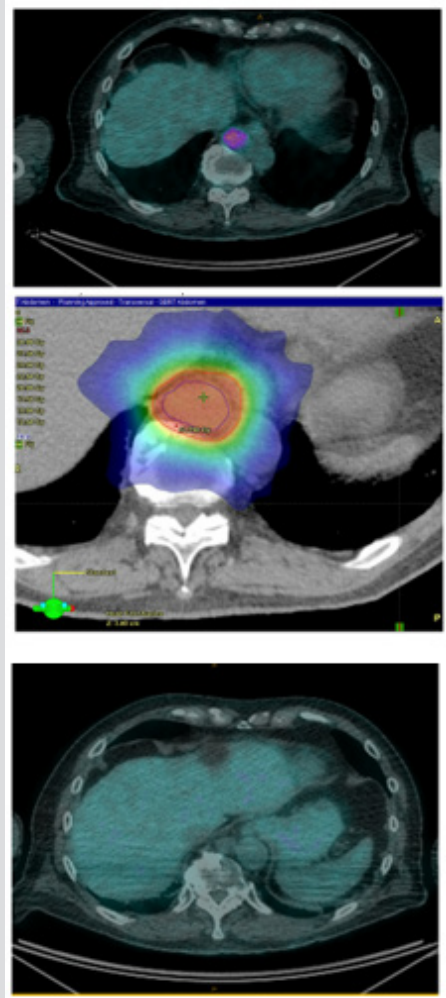

Figure 1: Resolution of PET-positive recurrence with RT and immunotherapy in patient 3.

a) A routine PET surveillance scan, at 24 months post primary diagnosis, revealed a $3 \mathrm{~cm}$ solitary distant recurrence with SUV 6.8 maximum in the para-aortic lymph nodes that had arisen within 3 months from the last PET.

b) Dosimetry of SBRT treatment plan.

c) Complete resolution of PET-positive disease one month post SBRT with immunotherapy. 


\section{Case Four}

An 85-year-old woman with palpable lymph nodes of biopsyproven MCC in the left groin from an unknown primary that was staged as TxN1. Baseline PET showed no other disease. She was treated with definitive RT, to a total dose of 50Gy in 25 fractions with complete resolution of the nodal disease. Routine follow-up with PET scan at 12 months showed multiple distant recurrences, higher up the para-aortic chain, and she was treated with radical intent immunotherapy and RT, and continues with stable disease, 33 months post original diagnosis.

\section{Case Five}

A 64-year-old male had an ear ache for 12 months and eventually had right temporal bone excision and superficial parotidectomy and selective radical neck dissection for a $14 \mathrm{~mm}$ mixed MCC/squamous cell carcinoma primary of the ear canal, resected with a $2 \mathrm{~mm}$ margin. None of the 78 lymph nodes were involved in the neck dissection, staged as T1N0. He was treated with adjuvant RT of 50Gy in 25 fractions to the left face and neck. Routine surveillance PET done six months following RT showed multiple distant recurrences with liver metastases, and he was treated with immunotherapy. An MRI brain scan performed a year later due to symptoms showed multiple brain metastases and he was treated with palliative intent with further RT, now years out from primary diagnosis with progressive disease. The relevant details for these patients are shown in Table 1. The female to male ratio was 3:2; average age was 73 years with a range 64 to 84 years; three had a head and neck primary, two had a limb primary; three were initially staged T1N0; four were initially treated with both surgery and RT. Average time to recurrence was with a range of 6 to 24 months. Majority failed with distant recurrence, and four had further radical intent treatment including immunotherapy. None of these patients were immunosuppressed.

Table 1: Case series of 5 asymptomatic MCC patients with positive surveillance PETs that changed management.

\begin{tabular}{|c|c|c|c|c|c|c|c|}
\hline Pt & Sex/Age & $\begin{array}{l}\text { Primary } \\
\text { Site and Size } \\
(\mathrm{mm})\end{array}$ & $\begin{array}{c}\text { Initial } \\
\text { Stage } \\
\text { (ajcc 8 } 8^{\text {th }} \text { Ed) }\end{array}$ & $\begin{array}{l}\text { Initial } \\
\qquad \mathbf{R x}\end{array}$ & +ve Pet at Months & $\begin{array}{c}\text { Pet } \\
\text { Findings }\end{array}$ & $\begin{array}{c}\text { Management Change on } \\
\text { Basis of Pet } \\
\text { /Intent }\end{array}$ \\
\hline 1 & $\mathrm{~F} / 64$ & $\begin{array}{l}\text { Eyelid/ } \\
5 \mathrm{~mm}\end{array}$ & T1N0 & $\mathrm{Sx}+\mathrm{RT}$ & 6 & $\begin{array}{l}\text { Regional } \\
\text { recurrence }\end{array}$ & $\begin{array}{c}\mathrm{Sx}+\mathrm{RT} \text {, Immuno } \\
\text { /radical }\end{array}$ \\
\hline 2 & $\mathrm{M} / 81$ & $\begin{array}{l}\text { Finger/ } \\
10 \mathrm{~mm}\end{array}$ & T1N0 & $\mathrm{Sx}+\mathrm{RT}$ & 24 & $\begin{array}{l}\text { Solitary } \\
\text { distant } \\
\text { recurrence }\end{array}$ & $\begin{array}{l}\text { RT/Immuno } \\
\text { /radical }\end{array}$ \\
\hline 3 & $\mathrm{M} / 73$ & $\begin{array}{l}\text { Thigh/ } \\
15 \mathrm{~mm}\end{array}$ & T1pN1a & $\mathrm{Sx}+\mathrm{RT}$ & 24 & $\begin{array}{l}\text { Solitary } \\
\text { distant } \\
\text { recurrence }\end{array}$ & $\begin{array}{c}\text { Immuno/RT } \\
\text { /radical }\end{array}$ \\
\hline 4 & $\mathrm{~F} / 85$ & $\begin{array}{c}\text { Groin/ } \\
\text { Unk primary }\end{array}$ & TxN1 & RT & 12 & $\begin{array}{l}\text { Multiple } \\
\text { distant } \\
\text { recurrence }\end{array}$ & $\begin{array}{c}\text { Immuno/RT } \\
\text { /radical }\end{array}$ \\
\hline 5 & $\mathrm{M} / 64$ & $\begin{array}{c}\text { Ear canal/ } \\
14 \mathrm{~mm}\end{array}$ & T1N0 & $\mathrm{Sx}+\mathrm{RT}$ & 6 & $\begin{array}{l}\text { Multiple } \\
\text { distant } \\
\text { recurrence }\end{array}$ & $\begin{array}{l}\text { Immuno/RT } \\
\text { /palliative }\end{array}$ \\
\hline Summary & $\begin{array}{l}\text { F:M ratio } \\
\text { 3F:2M; Aver- } \\
\text { age age (yrs; } \\
\text { range) } \\
\text { 73(64-84) }\end{array}$ & $\begin{array}{l}3 \text { head and } \\
\text { neck; } 2 \text { limbs }\end{array}$ & $4 \mathrm{x} \mathrm{T} 1$ & $4 x S x+R T$ & $\begin{array}{l}\text { Average time to re- } \\
\text { currence (months; } \\
\text { range) } \\
14(6-24)\end{array}$ & $\begin{array}{l}\text { Majority had dis- } \\
\text { tant recurrence }\end{array}$ & $\begin{array}{l}4 \text { had further radical intent } \\
\text { treatment }\end{array}$ \\
\hline
\end{tabular}

Note: $\mathrm{AJCC}=$ American Joint Committee on Cancer $; \mathrm{F}=$ female; Immuno = Immunotherapy; $\mathrm{M}=\mathrm{Male} ; \mathrm{mm}=\mathrm{Millimetre} ; \mathrm{Pt}=$ Patient; $\mathrm{RT}=$ Radiotherapy; $\mathrm{Rx}=$ Treatment; $\mathrm{Sx}=$ Surgery; Unk = Unknown $; \mathrm{yrs}=$ Years; +ve = positive. 


\section{Discussion}

In this series, five radically-treated cases of MCC had a surveillance PET scan when asymptomatic. This scan discovered more disease and as a result, changed management as described. These five represent $25 \%$ of radically treated cases (5/20) and $20 \%$ of all cases (5/25) treated from 2014-2018 coming from a single clinician's practice. The majority had T1N0 lesions initially, but still failed distantly at an average time of 14 months. Surveillance PET scanning when asymptomatic allowed for repeat radical intent treatment involving immunotherapy. All were still alive at the time of audit. This series adds to the evidence that surveillance PET scan impacts management, and therefore, should be reimbursed.

Previous studies in PET in MCC have been done. Poulsen et al. [10] found that staging FDG-PET significantly influenced treatment decisions in approximately one-third of cases of MCC and should be considered in the routine pre-treatment work-up. Post-treatment PET was not found to be prognostic. A retrospective review by Iagaru et al. [12] of six patients diagnosed with MCC, who had twelve PET/ CT scans performed on them, identified nine true positive lesions, seven true negative lesions, one false positive lesion and one false negative lesion. From this, the authors concluded that PET/CT may have a role in initial staging and post-therapy surveillance but warrants further studies. Yao et al. [13] in 2 patients found surveillance PET useful in predicting early relapse. The preferred protocol for this clinician is surveillance PET scans every 6 months. This protocol is hard to enforce when patients have to self-fund, so the protocol was not strictly adhered too. Some had less scans, some had more. If the protocol was adhered to, perhaps more would benefit. Reimbursement may help protocol compliance. MCC has a mortality rate higher than melanoma [1,2]. PET for surveillance in melanoma is reimbursed by Medicare, the Australian health care funder, but not reimbursed in MCC. It is even more difficult to encourage self-funding when there is lack of evidence in this rare tumour. This study provides this and also adds weight to the call by Poulsen et al. [10] that reimbursement needs to be considered for MCC in both staging and surveillance.

\section{Conclusion}

This retrospective study of a single clinician's practice shows that surveillance PET scans may change management in up to $25 \%$ of asymptomatic radically treated patients with MCC, allowing further radical treatment of the majority. Protocol compliance may be increased if surveillance PET scans in MCC are reimbursed.

\section{Disclosures}

GBF-Advisory board 2017, 2018 Merck Serono Australia Pty Ltd; Grant recipient 2018 Merck Serono Australia Pty Ltd; Shareholder, Genesis Care 2008-current.

\section{Acknowledgements}

This work is supported by Genesis Care NSW. We acknowledge the Cancer Australia, Support for Cancer Clinical Trials Program, which has provided financial and other support to Melanoma and Skin Cancer (MASC) Trials Limited.

\section{References}

1. Houben R, Schrama D, Becker JC (2009) Molecular pathogenesis of Merkel cell carcinoma. Experimental Dermatology 18(3): 193-198.

2. Toker C (1972) Trabecular Carcinoma of the Skin. Arch Dermatol 105(1): 107-110.

3. Schadendorf D, Lebbé C, Zur Hausen A, Avril MF, Hariharan S, et al. (2016) Merkel cell carcinoma: Epidemiology, prognosis, therapy and unmet medical needs. European Journal of Cancer 71: 53-69.

4. Girschik J, Thorn K, Beer TW, Heenan PJ, Fritschi L, et al. (2011) Merkel cell carcinoma in Western Australia: a population-based study of incidence and survival. British Journal of Dermatology 165: 1051-1057.

5. Kang SH, Haydu LE, Goh RY, Fogarty GB (2012) Radiotherapy is associated with significant improvement in local and regional control in Merkel cell carcinoma. Radiat Oncol 17(7): 171.

6. Agelli M, Clegg LX (2003) Epidemiology of primary Merkel cell carcinoma in the United States. Journal of the American Academy of Dermatology 49(5): 832-841.

7. Feng H, Shuda M, Chang Y, Moore PS (2008) Clonal Integration of a Polyomavirus in Human Merkel Cell Carcinoma. Science 319(5866): 1096-1100.

8. Lebbe C, Becker JC, Grob JJ, Malvehy J, Del Marmol V, et al. (2015) Diagnosis and treatment of Merkel Cell Carcinoma. European consensusbased interdisciplinary guideline. European Journal of Cancer 51(16): 2396-2403.

9. Hui AC, Stillie AL, Seel M, Ainslie J (2008) Merkel Cell Carcinoma 27-Year Experience at the Peter MacCallum Cancer Centre. International Journal of Radiation Oncology 72(1): 121-122.

10. Poulsen M, Macfarlane D, Veness Mss (2018) Prospective analysis of the utility of 18-FDG PET in Merkel cell carcinoma of the skin: A TransTasman Radiation Oncology Group Study, TROG 09:03. J Med Imaging Radiat Oncol 62(3): 412-419.

11. Bichakjian CK, Nghiem P, Johnson T (2017) Merkel Cell Carcinoma. In: Amin MB, Edge S, Greene FAJCC Cancer Staging Manual. ( $8^{\text {th }}$ edn.) Springer International Publishing: American Joing Commision on Cancer.

12. Iagaru A, Quon A, Mcdougall IR, Gambhir SS (2006) Merkel cell carcinoma: Is there a role for 2-deoxy-2-[f-18] fluoro-D-glucose-positron emission tomography/computed tomography? Mol Imaging Biol 8(4): 212-217.

13. Yao M, Smith RB, Hoffman HT, Funk GF, Graham MM, et al. (2005) Merkel cell carcinoma: two case reports focusing on the role of fluorodeoxyglucose positron emission tomography imaging in staging and surveillance. Am J Clin Oncol 28(2): 205-210. 


\section{ISSN: 2574-1241}

DOI: 10.26717/BJSTR.2019.16.002841

Gerald B Fogarty. Biomed J Sci \& Tech Res

(c) (9) This work is licensed under Creative Commons Attribution 4.0 License

Submission Link: https://biomedres.us/submit-manuscript.php

\begin{tabular}{ll} 
BIOMEDICAL & \multicolumn{1}{c}{ Assets of Publishing with us } \\
RESEARCHES & - Global archiving of articles \\
\hline ISSN:2574-1241 & - Immediate, unrestricted online access \\
& - Rigorous Peer Review Process \\
\end{tabular}

